\title{
The Hemeostatic Efficacy of ANKAFERD after Excision of Full Thickness Burns: A Comparative Experimental Study in Rats
}

\author{
Yusuf Kenan Coban ${ }^{1}$, Elif Ozerol' ${ }^{2}$, Kevser Tanber ${ }^{2}$, Serkan Erbatur ${ }^{1}$, \\ Ahmet Hamdi Aytekin ${ }^{1}$, Cemal Firat ${ }^{1}$ \\ ${ }^{1}$ Inonu Üniversity Medical Faculty, Department of Plastic \& Reconstructive Surgery and Burn Unit, Malatya, Turkey. \\ ${ }^{2}$ Inonu Üniversity Medical Faculty, Department of Biochemistry, Malatya, Turkey. \\ E-mail:ykenanc@yahoo.com \\ Received October 14, 2010; revised October 20, 2010; accepted October 24, 2010
}

\begin{abstract}
Objective: In order to evaluate the effects of Ankaferd blood stopper (ABS) on post-excisional burn wound bleeding via monitoring early blood hemoglobin level changes and to make a comparison with a standart topical treatment, a controlled experimental study was conducted. Design and Interventions: A contact burn model of full-thickness injury with 30\% TBSA was used. Following the burn injury, excisions of burned areas were done at postburn 48th hour. 24 male Spraque Dawley rats were divided into control, adrenaline, ABS-solution and ABS-pad treatment groups. In control group no treatment was done for bleeding, but the other three groups had topical treatments. Samples were taken at the begining of the study, just before and 1 hour after the burn wound excisions for measurement of haemoglobine $(\mathrm{Hb})$ levels and additionally the external bleeding amounts were measured by weighing the topical pads. Measurements and main results: Baseline $\mathrm{Hb}$ levels of control, adrenaline, ABS-solution and ABS-pad treatment groups were $15.06 \pm 0,83,15,82 \pm$ $0.83,16.23 \pm 1.14$ and $15.16 \pm 1.46$ respectively. At the 48th hour of postburn injury, the Hb levels of these groups were $13.82 \pm 0.58,13.68 \pm 1.26,13.79 \pm 0.90$ and $13.57 \pm 0.89$. Mean blood loss amounts (ml) after burn wound excisions in groups were $1.44 \pm 0.26,0.65 \pm 0.07,0.53 \pm 0.08$ and $0.44 \pm 0.09$. Conclusions: ABS was found to be as effective as topical adrenaline on reducing excisional bleeding in the experimental burn injury model.
\end{abstract}

Keywords: Ankaferd Blood Stopper, Burn Surgery, Bleeding

\section{Introduction}

Bleeding is a major problem during early excision of burned skin [1]. Reducing blood loss during burn surgery is important for decreasing patient morbidity from hemodynamic derangement and minimizing the risk of transfusion-associated infections [2]. Different techniques have been used to reduce the intraoperative blood loss in burn surgery including warm saline-soaked pads, topical solutions of thrombin with or without adrenaline, topical vasoconstructors, compressive dressings or tourniquets, and vasopressin continuous intravenous infusion $[3,4]$.

Ankaferd blood stopper (ABS) is a herbal extract which has been used historically as hemostatic agent in Traditional Turkish medicine. It comprises of standardized mixture of herbs Thymus vulgaris, Glycyrrhiza glaba, vitis vinifera, alpinia officinarum and urtica dioica. Exposure to ABS results in a very rapid formation of network within the plasma and serum without interfering with any individual clotting factor [5]. ABS seems to be effective in bleeding control in different tissue injuries.

We tested the hypothesis that ABS could be useful agent for decreasing blood loss after post-burn wound excision in a randomized, controlled experimental study. Change in blood hemoglobin levels was used as a primary outcome as well as actual blood loss, as it has been shown that changes in hemoglobin levels is strictly correlates with physiologic parameters of hemorrhage [6].

\section{Methods}

24 young adult male spraque-dawley rats (mean weight 
$200 \pm 20$ gram) obtained from Inonu University Animal Research Center were used in the study. The animals were kept in a room at a constant temperature of $21^{\circ} \mathrm{C} 12$ $\mathrm{h}$ dark and $12 \mathrm{~h}$ light cycle and fed standard pellet chow and water, which were avaliable ad libitum. The study protocol (Figure 1) was approved by Institutional Ethical Committe (approval no: 2009-25). The experimental project was furtherly supported by Inonu University Scientific Research Foundatition (project number, 2010/38). All the rats were allowed free to take water and ad libitum for post-injury days. Three rats were housed in each cage during postburn management. The animals were divided randomly into four groups as control, adrenaline, ABS solution, and ABS pad.

Prior to burn injury, the animals were anesthesized with ketamine hydrochloride and xylazine hydrochloride. Dorsum of each rat was shaved with an electrical clipper and then the area was burned in order to obtain $30 \%$ TBSA of full-thickness burn injury.

A comb burn model of full-thickness injury with intervening unburned interspaces was used. The method depended on contact burn injury using a metal brass thomb heated in boiling water. The dimensions of the brass comb were $20 \times 20 \times 60 \mathrm{~mm}$, with four $10 \times 20-$ $\mathrm{mm}$ rectangular prongs separated by three 5 -mm-wide grooves. The brass comb was preheated in boiling water $\left(100^{\circ} \mathrm{C}\right)$ for 5 minutes and applied without pressure on one side of the back for a period of 3 minutes [7].

\subsection{Resuscitation Fluid Formulation and Its Estimation}

Following to the burning insult, serum physiologic was subcutaneously given to each rat's dorsal neck region at a rate of " $4 \times \mathrm{kg} \times$ burn percentage" for fluid resuscitation. The amount of resuscitation fluid used for each rat was:

$$
4 \times 0,20 \mathrm{~kg} \times 30=24 \pm 2 \mathrm{cc}
$$

for the first day.

Body surface area is difficult to measure in small laboratory animals. It is therefore estimated as surface area $\left(\mathrm{cm}^{2}\right)=10 \times$ Mass $\left(\mathrm{g}^{0.66}\right)$. The prefactor " $10 "$ is empirically adjusted. The prefactor for rats is 9.1. Therefore to find the surface area of a rat, plug its mass into the equeation $9.1 \times$ gram ${ }^{0.66}$. So "a 300 gram rat" would have a surface area of $392.6 \mathrm{~cm}^{2}$ [8,9]. In our model $87 \mathrm{~cm}^{2}$ would corresponds to $30 \%$ of TBSA, as our average rat weight was 200 gr. The preheated brass comb was applied to the dorsum in order to obtain a mixed contact burn area of $87 \mathrm{~cm}^{2}$ in repeating sessions.

At the 48 th hour of postburn, the burned areas were excised with using surgical blade no.10 under ketamine (Alfamine, Alfasan, Nedherland) and Xylazine Hcl (Al- fazyne $2 \%$, Alfasan, Nedherland) anesthesia. Ketamine and xylazine was given to the rats at dose of $50 \mathrm{mg} / \mathrm{kg}$ and $5 \mathrm{mg} / \mathrm{kg}$ intraperitoneally in each session. No electrocautery was used during burn wound excision. The topical treatments were started just after the completition of surgical debridement in all groups, which were epinephrine or Ankaferd soaked gauze and ankaferd pads or simply serum physiologic soaked gauzes application to the wounds following to debridements. In adrenaline group, the required amount of epinephrine solution (Adrenalin $0.25 \mathrm{mg} / \mathrm{ml}$, Biofarma, Turkey) was diluted 1:10 with saline (concentration $0.025 \mathrm{mg} / \mathrm{ml}$ ). Bleeding or oozing amounts were also macroscopically recorded, photographized and measured in each group (Figure 2).

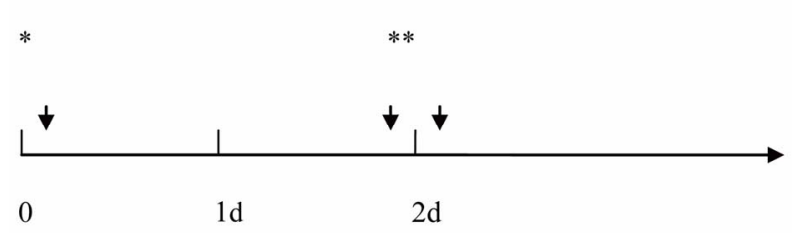

Figure 1. Experimental protocol. *Burn injury on rats; **Burn wound excision time. Black arrows: timing of obtaining blood samples for hemoglobin measurements, zero time, just before burn wound excision and 1 hour later at the second postburn day. 1d; First day, 2d; second day

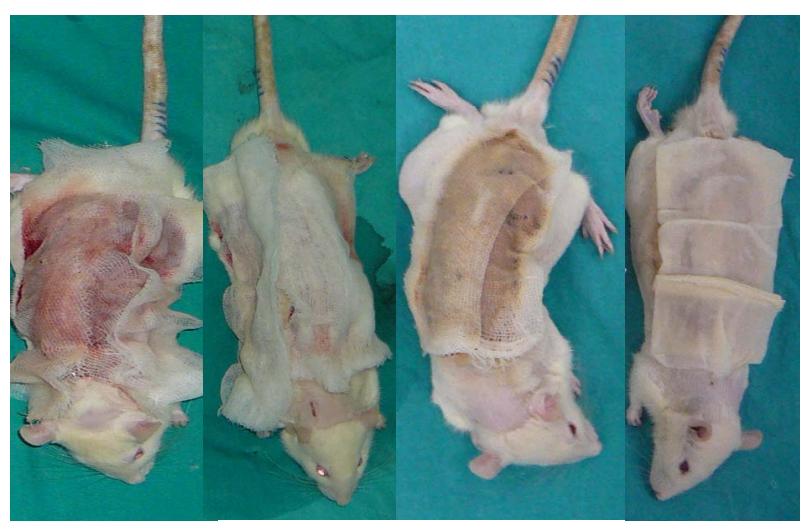

Figure 2. A-Typical bleeding or oozing from debridementsites in rats: from left to right are control, adrenaline, ABSsoaked gauze, ABS pad.

\subsection{Amount of Bleeding Estimation}

The amount of bleeding was measured by means of a soaked gause. The blood was collected on soaked gause, which was weighed before and after the procedure on a $0.1 \mathrm{~g}$ accurate scale. The difference in the weight of the gause before and after the procedure indicated the amount of bleeding. The application time over the bleeding area varied between 45 minutes and 1 hour. 


\subsection{Measurement of Hemoglobin Concentration in Whole Blood and Blood Sampling}

Hemoglobin levels were measured preoperatively, at the second day of postburn and $1 \mathrm{~h}$ after completion of the operation. For measurement of hemoglobin concentration in whole blood, samples of $0.5 \mathrm{cc}$. were taken from hearts of each rat into containers. Lower hemoglobin concentrations were found in heart blood than in the tail blood of small rats (less than $100 \mathrm{~g}$ body weight). It has been shown that there was no significant difference in the haemoglobin values of blood taken from the tail or from the heart in large rats [10].

The blood samples were send rapidly for hemoglobin analysis in each session. After obtaining the third and the last blood samples, all the rats were sacrified.

The levels of hemoglobin in blood were estimated by using the cyanomethemoglobin method described by Drabkin in a spectrophotometer [11]. Drabkin's solution on mixing with whole blood converts Hemoglobin to Cyanomethemoglobin. The absorbance of Cyanomethemoglobin is proportional to the Hemoglobin concentration. Drabkin's solution contains potassium ferricyanide, potassium cyanide and sodium bicarbonate. This method is simple, rapid and reliable and measures all types of hemoglobin except sulfohemoglobin.

\subsection{Statistical Analysis}

The data were presented as mean \pm standart deviance. A software system of SPSS 11.0 version was used statistical analysis. ANOVA and posthoc Tukey test were used for multiple comparisions between the groups. Wilcoxon Signed Rank test was used for comparision of repeated measures of blood hemoglobin levels. A P value less than 0,05 was accepted as significant.

\section{Findings}

$\mathrm{Hb}$ levels measured separately in three sessions is shown in Table 1. Hb levels at the begining of study did not differ between the groups $(p>0.05)$. Hb levels obtained after two days of burn injury did not also show any difference between the groups, but significantly decreased in comparision of previous values in all groups (Wilcoxon signed rank test, $\mathrm{p}<0.05)$. Hb levels obtained 1 hour following to burn excisions from control group was significantly lower than three other groups $(p<0.05)$. There was no difference between the groups of $\mathrm{A}$, ABS-S, and ABS-P with respect to $\mathrm{Hb}$ levels obtained at third session $(\mathrm{p}>0.05)$.

There were significantly higher amounts of blood loss in group $C$ than other three groups $(p>0.05)$. A, ABS-S
Table 1. Hemoglobin levels and blood loss amounts in groups, and multiple comparisons with ANOVA.

\begin{tabular}{ccccc}
\hline Groups & $H B 1(\mathrm{~g} / \mathrm{dl})$ & $H B 2(\mathrm{~g} / \mathrm{dl})$ & $H B 3(\mathrm{~g} / \mathrm{dl})$ & $\begin{array}{c}\text { Blood loss } \\
(\mathrm{ml})\end{array}$ \\
\hline C & $15.06 \pm 0.83$ & $13.82 \pm 0.58$ & $11.08 \pm 0.79$ & $1.44 \pm 0.26$ \\
A & $15.82 \pm 1.13$ & $13.68 \pm 1.26$ & $12.70 \pm 055$ & $0.65 \pm 0.07$ \\
ABS-S & $16.23 \pm 1.14$ & $13.79 \pm 0.90$ & $12.99 \pm 0.83$ & $0.53 \pm 0.08$ \\
ABS-P & $15.16 \pm 1.46$ & $13.57 \pm 0.89$ & $12,57 \pm 0,76$ & $0.44 \pm 0.09$ \\
P & & & & \\
C-A & N.S. & N.S. & 0.007 & 0.001 \\
C-ABS & N.S. & N.S. & 0.001 & 0.001 \\
C-ABS pad & N.S. & N.S. & 0.012 & 0.001 \\
A-ABS & N.S. & N.S. & N.S. & N.S. \\
A-ABS pad & N.S. & N.S. & N.S. & N.S. \\
ABS-ABS & N.S. & N.S. & N.S. & N.S. \\
pad & & & & \\
\hline
\end{tabular}

N.S. non significant, (According to posthoc Tukey test). C: Control, A: Adrenaline, ABS-S: Ankaferd blood stopper solution, ABS-P:Ankaferd blood stopper pad. HB1: first hemoglobin measurements, HB2 second and HB3 third measurements.

and ABS-P groups showed no difference with respect to blood loss amounts $(\mathrm{p}>0.05)$.

\section{Results and Discussion}

Topical hemostatic products containing thrombin are commonly used in burn surgery to facilitate focal hemostasis and graft adherence. But using these agents sometimes may encounter with unexpected clinical complications. One example to this type of clinical problem has been reported by Foster et al. They found coagulopathy due to factor $\mathrm{V}$ deficiency as evidenced by excessive bleeding and abnormal coagulation parameters following to repeated applications epineprine solution containing bovine thrombin in a severe burn patient with $75 \%$ TBSA [12].

A restrictive blood transfusion strategy and the use of hemostatic agents may decrease morbidity and mortality in trauma and burn patients [13]. Kahalley was the first to report diminished intraoperative blood loss with subcutaneous injection of a saline-vasopressor solution under donor sites and debrided areas without severe systemic side reactions [14]. This clinical observation was further supported with others especially for children with burn $[15,16]$. Minimal absorption of adrenaline without systemic effects using a tumescent technique has been described. This technique was later modified and found to be effective in reducing the intraoperative and total blood transfusion requirements in thermally injured patients [17]. Anthony et al. studied the effects of adrenaline on hemodynamics and markers of tissue perfusion in burned patient with comparing non-burned controls included mostly adult age group of patients [18]. They found increased heart rate, elevated adrenaline serum levels up to $6 \mathrm{~h}$, and hiperlactatemia lasting up to $4 \mathrm{~h}$ fol- 
lowing to topical adrenaline application. Although the use of topical adrenaline still seems to be a safe way to be used in burned patients, its potential dangerous side effects do not make it an ideal haemostatic agent.

Newer products are under investigation for finding the most ideal haemostatic agent. In vitro studies evaluating the haemostatic effects of ABS have shown that its addition to plasma and normal serum has resulted in formation of an encapsulating protein mesh that acts as a matrix within which erythrocyte aggregation occurs in a very fast way (less than a second) [19]. Several animal studies of different experimental models including incisional or excisional traumas have revealed its efficacy in stopping the bleeding in vivo [20,21].

There are many prospective, retrospective or/and case-control series studies in which ABS was effective to stop neoplastic gastrointestinal bleedings, epistaxis, bleeding after knife tonsillectomies, active cutaneous- subcutaneous incisional bleedings and bleedings where endoscopic variceal ligation failed [22-24]. Clinical reports are also present of successful ABS usage via endoscope or oral and rectal routes in gastrointestinal system haemorrhagies in where optimal bleeding control could not be achieved in spite of endoscopic adrenaline injection and argon plasma coagulation $[25,26]$.

We chose to have $30 \%$ TBSA in the model, so as to have a prominent $\mathrm{Hb}$ decline without causing fatal serious morbidity. Other reasons for chosing this model are following: First, actual burn injuries seen in clinical practice are mixed, i.e. some body areas with full-thickness and some with uninjured. So the model reflects much actual burn clinical scenario. Second, it is cheaper and relatively safe for investigators [27]. Fatherly, over the course of next few days after injury most of these ischemic interspace progresses to full-thickness necrosis. The model has also been shown that gross visual appearance is good indicator of whether necrosis is truly present as evidenced histopathologically 7 days after injury. Resuscitation fluid was given subcutaneously instead of giving intraperitoneally, because it has been shown that subcutaneous fluid administration as means of rehydration is effective in other species including humans [8]. It has also been shown that prophylactic fluid administered mice via subcutaneous route have improved survival times after carcinogen treatment [9]. Burn wound excision was done at 48th hour of postburn injury, so that a closer resembling of early excision in a clinical picture as early tangential excision of deep burns is a widely accepted treatment modality. The decrease of $\mathrm{Hb}$ levels seen in control group after burn wound excision was not observed in adrenaline and ABS treament groups $(\mathrm{p}<0.05)$.

ABS would be an advantage in traditional theraphies on several aspects. It has antimicrobial and antifungal effects which was demonstrated by several in vitro studies [28,29]. A novel finding of which ABS was found to be inhibitory for MRSA, Acinetobacter, E. Coli and Pseudomanas species growth was reported by Saribas et al recently. This is very important, as most of these organisms are responsible for burn wound sepsis [30].

Regarding to the effects of ABS on wound healing, literature is scarce. Isler et al. reported ABS decreased the inflammation and necrosis process and increased the new bone formation in early bone healing period without causing any foreign body reaction [31]. ABS application time was only 1 hour in our study. We did not see any adverse effects during the observation and could not make any conclusion on wound healing. In an observational clinical study, Ozaslan et al. revealed that endoscopic application of ABS as a primary therapy in patients with bleeding due to chronic radiation proctitis was found to be effective in healing radiation induced ulcers [32]. The authors had also confirmed their finding with another case report [33]. For now, the effects of ABS on wound healing seem to be limited by the observation of a decreasing effect on microvessel density measurements in the tissue exposed to ABS, which suggest the presence of secondary more sustained mechanism of hemostasis besides the initial protein network [34].

Exposure to ABS in a certain area provides physiological hameostasis process together with tissue oxygenation without calling out any individual coagulation factor. This unique mechanism advantage provides advantage to ABS compared with others. Bleeding models in animals pretreated with aspirin, warfarin or heparin revelaed that $\mathrm{ABS}$ had effectively reduced the duration and amount of bleeding $[35,36]$. Another most striking effect of ABS is its in vitro positive effects over mesenchymal stem cell proliferation as shown by Kilic et al. [37]. This would be another potential advantage of this natural substance over traditional therapies, because a severe regenerative process is needed during recovery phase of massive burn injury.

\section{Conclusion}

Burned patients have a consumption coagulopathy which, in combination with haemodilution during operation results in a clinically significant deficiency of coagulation factors II, VII and X [38]. Any hemostatic agent that does not interfere with coagulation factors would take the advantage over other hemostatically active products. The levels of coagulation factors II, VII, IX, X, XI, and XIII were not affected by ABS [39]. Furthermore, ABS as an adjunctive drug has been shown to treat a challenging upper gastrointestinal bleeding case with a low 
platelet count [40]. Fibrinogen appears not to be a necessary component for formation of the protein network of ABS, as it was found to be effective in a patient with afibrinogenemia [41]. Overt disseminated intravascular coagulation in which hypofibrinogenemia occurs due to cosumtion cougulopathy seem to occur in critically ill burn patients $[42,43]$. So the use of ABS in severe burn patients with third degree injury may be useful adjunctive measure to prevent fulminant course.

The experimental study supports the use of ABS in achieving hemostasis in intraoperative managent of blood loss at burn wound excision site and but further studies are needed to clearify the effects of ABS on other parameters in burn management.

\section{References}

[1] M. J. Jankiewicz, "Consensus Summary on Excisional Therapy," In: G. T. Shires, E. A. Black, Eds., Proceedings of the NIH Consensus Development Conference in Supportive Therapy in Burn Care, Journal of Trauma, Vol. 19, Sup. 11, 1979, pp. 933-934.

[2] W. L. Garner, P. D. Thomson, N. P. Moore, et al., "Effect of Triglycyl-Lysine-Vasopressin on Skin Blood Flow and Blood Loss during Wound Excision in Patients with Burns," Journal of Burn Care \& Rehabilitation, Vol. 14, No. 4, 1993, pp. 458-460. doi:10.1097/00004630-199307000-00011

[3] B. S. Brezel, K. E. McGreever, J. M. Stein, et al., "Epinephrine V Thrombin for Split Thickness Donor Site Haemostasis," Journal of Burn Care \& Rehabilitation, Vol. 8, No. 2, 1987, pp. 132-134. doi:10.1097/00004630-198703000-00009

[4] D. M. Heimbach and L. H. Engrav, "Surgical Management of the Burn Wound," Raven Press, New York, 1984.

[5] H. C. Firat, O. Ozdemir, A. Kosar, H. Goker and I. C. Haznedaroglu, "Annual Review of Ankaferd 08-09," Naviga Scientific Publications, Istanbul, 2009, pp. 13-15.

[6] B. Bruns, M. Lindsey, K. Rowe, S. Brown, J. P. Minei, L. M. Gentilello and S. Shafi, "Haemoglobin Drops within Minutes of Injuries and Predicts Need for an Intervention to Stop Hemorrhage," Journal of Trauma, Vol. 63, No. 2, 2007, pp. 312-315. doi:10.1097/TA.0b013e31812389d6

[7] A. J. Singer, S. A. McClain, B. R. Taira, A. Romanov, J. Rooney and T. Zimmerman, "Validation of a Porcine Comb Burn Model," American Journal of Emergency Medicine, Vol. 27, No. 3, March 2009, pp. 285-288. doi:10.1016/j.ajem.2008.02.019

[8] R. Nobel-Adams, "Dehydration, Subcutaneous Fluid Administration," British Journal of Nutrition, Vol. 4, No. 9, 1995, pp. 488-494.

[9] D. E. Smith, J. B. Blumberg and R. D. Lipman, "Improved Survival Rates in Mice that Received Prophylactic Fluids after Carcinogen Treatment," American Association for Laboratory Animal Science, Vol. 38, No. 1, 1999, pp. 84-86.
[10] B. H. Doell, "Hegarty. The Haemoglobin Concentration of Peripheral and Central Blood of the Laboratory Rat," Vol. 18, No. 5, 1970, pp. 503-510.

[11] V. Fairbanks and G. G. Klee, "Biochemical Aspescts of Haematology, In: C. A. Burtis and E. R. Ashwood, Eds, Tietz of Clinical Chemistry, Philadelphia, W.B. Saunders, 1994, pp. 2010-2021.

[12] K. N. Foster, H. Kim, K. Potter, M. R. Matthews, M. Pressman and D. M. Carusso, "Aquired Factor V Deficiency Associated with Exposure to Bovine Thrombin in a Burn Patient," Journal of Burn Care \& Rehabilitation, Vol. 31, No. 2, 2010, pp. 353-360. doi:10.1097/BCR.0b013e3181d0f5b4

[13] G. P. Fraga, V. Bansal and R. Coimbra, "Transfusion of Blood Products in Trauma: An Update," Journal of Emergency Medicine, Vol. 39, No. 2, 2010, pp. 253-260. doi:10.1016/j.jemermed.2009.02.034

[14] L. Kahalley, A. R. Dimick and R. W. Gillespie, "Methods to Diminish Intraoperative Blood Loss," Journal of Burn Care \& Rehabilitation, Vol. 12, No. 2, 1991, pp. 160-161. doi:10.1097/00004630-199103000-00015

[15] R. L. Sheridan and S. K. Szyfelbein, "Staged High-Dose Epinephrine Clysis is Safe and Effective in Extensive Tangential Burn Excisions in Children," Burns, Vol. 25, No. 8, 1999, pp. 745-748. doi:10.1016/S0305-4179(99)00088-1

[16] R. D. Robertson, P. Bond, B. H. Wallace, K. Shewmake and J. B. Cone, "An Analysis of the Tumescent Technique in Tangential Excision and Autografting," Journal of Burn Care \& Rehabilitation, Vol. 18, No. 1, Part 3, 1997, p. $\mathrm{S} 152$.

[17] M. Gomez, S. Logsetty and J. S. Fish, "Reduced Blood Loss during Burn Surgery," Journal of Burn Care \& Rehabilitation, Vol. 22, No. 2, 2001, pp. 111-117. doi:10.1097/00004630-200103000-00005

[18] A. A. Papp, A. V. Uusaro and E. T. Ruokonen, "The Effects of Topical Epinephrine on Haemodynamics and Markers of Tissue Perfusion in Burned and Non-Burned Patients Requiring Skin Grafting," Burns, Vol. 35, No. 6, 2009, pp. 832-839. doi:10.1016/j.burns.2008.10.001

[19] B. Z. Haznedaroglu, I. C. Haznedaroglu, S. L. Walker, H. Bilgili, H. Goker, A. Kosar, A. Aktas, O. Captug, M. Kurt, O. Ozdemir, S. Kirazli and H. C. Firat, "Ultrastructural and Morphological Analyses of the in vitro and in vivo Hemostatic Effects of Ankaferd Blood Stopper," Clinical and Applied Thrombosis/Hemostasis, Vol. 16, No. 4, 2010, pp. 446-453. doi:10.1177/1076029609343706

[20] H. Bilgili, A. Kosar, M. Kurt, I. K. Onal, H. Goker, O. Captug, A. Shorbagi, M. Turgut, M. Kekilli, O. K. Kurt, S. Kirazli, S. Aksu and I. C. Haznedaroglu, "Hemostatic Efficacy of Ankaferd Blood Stoper in a Swine Bleeding Model," Medical Principles and Practice, Vol. 18, No. 3, 2009, pp. 165-169. doi:10.1159/000204344

[21] E. Huri, T. Akgül, A. Ayyildiz, H. Ustün and C. Germiyanoğlu, "Hemostatic Role of a Folkloric Medicinal Plant Extract in a Rat Partial Nephrectomy Model: Controlled Experimental Trial," Journal of Urology, Vol. 181, No. 5, 2009, pp. 2349-2354. doi:10.1016/j.juro.2009.01.016 
[22] M. Kurt, I. Oral, M. Akdogan, N. Kekilli, M. Arhan, A. Sayılır, E. Oztas and I. C. Haznedaroglu, "Ankaferd Blood Stopper for Controlling Gastrointestinal Bleeding Due to Distinct Bening Lesions Refraftory to Conventional Antihemorrhagic Measures," Canadian Journal of Gastroenterology, Vol. 24, No. 6, 2008, pp. 380-384.

[23] B. Al, C. Yıldırım, M. Cavdar, S. Zengin, H. Buyukaslan and M. E. Kalender, "Effectiveness of ABS in the Topical Active Bleeding Due to Cutaneous-Subcutaneous Incisions," Saudi Medicine Journal, Vol. 30, No. 12, 2009, pp. $1520-1525$.

[24] A. Karaman, E. Torun, S. Gursoy, A. Yurci and O. Ozbakir, "Efficacy of Ankaferd Blood Stopper in Postpolypectomy Bleeding," Journal of Alternative and Complementary Medicine, Vol. 16, No. 10, 2010, pp. 1027-1028. doi:10.1089/acm.2010.0089

[25] M. Kurt, S. Dişibeyaz, M. Akdoğan, N. Sasmaz, S. Aksu and İ. C. Haznedaroğlu, "Endoscopic Application of ABS as a Novel Experimental Modality for Upper Gastrointestinal Bleeding: A Case Report," American Journal of Gastroenterology, Vol. 103, No. 8, August 2008, pp. 21562158. doi:10.1111/j.1572-0241.2008.01982_15.x

[26] M. Ibıs, M. Kurt, İ. K. Onal, M. Kekilli and İ. C. Haznedaroğlu, Succesfull Management of Bleeding Due to Solitary Rectal Ulcer via Topical Application of ABS," Journal of Alternative and Complementary Medicine, Vol. 14, No. 9, 2008, pp. 1073-1074. doi:10.1089/acm.2008.0314

[27] R. Gurfinkel, A. J. Singer, E. Cagnano and L. Rosenberg, "Development of a Novel Animal Burn Model Using Radiant Heat in Rats and Swine," Academic Emergency Medicine, Vol. 17, No. 5, 2010, pp. 514-520. doi:10.1111/j.1553-2712.2010.00736.x

[28] N. Akkoc, M. Akcelik, I. Haznedaroglu, H. Goker, S. Aksu, S. Kirazli and H. Firat, "In vitro Anti-Bacterial Activities of Ankaferd Blood Stopper," International Journal of Laboratory Hematology, Vol. 30, Sup. 1, 2008, p. 95.

[29] N. Akkoc, M. Akcelik, I. Haznedaroglu, H. Goker, M. Turgut, S. Aksu, S. Kirazli and H. C. Firat, "In Vitro Antibacterial Activities of Ankaferd Medicinal Plant Extract," Türkiye Klinikleri tıp Bilimleri Dergisi, Vol. 29, No. 2, 2009, pp. 410-415.

[30] Z. Saribas, B. Sener, I. C. Haznedaroglu, G. Hascelik, S. Kirazli and H. Göker, "Antimicrobial Activity of Ankaferd Blood StopperA (R) against Nosocomial Bacterial Pathogens," Central European Journal of Medicine, Vol. 5, No. 2, 2010, pp. 198-202. doi:10.2478/s11536-009-0140-4

[31] S. C. Isler, S. Demircan, S. Cakaner, Z. Cebi, C. Keskin, M. Soluk and E. Yuzbasioglu, "Effects of Folkloric Medicinal Plant Extract Ankaferd Blood Stopper on Early Bone Healing," Journal of Applied Oral Science, Vol. 18, No. 4, 2010, pp. 409-414.

[32] E. Ozaslan, G. Purnak, G. Ozy1git, F. Akyol, A. Yildız and I. C. Haznedaroglu, "No Prolonged Effect of ABS on Chronic Radiation Proctitis," Endoscopy, Vol. 42, Sup. 2, 2010, pp. E271-272.
[33] E. Ozaslan, T. Purnak, A. Yildız, T. Akar, U. Avcioglu and I. C. Haznedaroglu, "The Effect of ABS on Severe Radiation Colitis," Endoscopy, Vol. 41, Sup. 2, 2009, pp. E321-E322.

[34] N. Turhan, M. Kurt, A. Shobagi, M. Akdogan and I. C. Haznedaroglu, "Topical Ankaferd Blood Stopper Administration to Bleeding Gastrointestinal Carcinomas Decreases Tumor Vascularisation," American Journal of Gastroenterology, Vol. 104, No. 11, 2009, pp. 2874-2877. doi:10.1038/ajg.2009.431

[35] H. S. Cipil, A. Kosar, A. Kaya, B. Uz, I. C. Haznedaroglu, H. Goker, O. Ozdemir, M. Koroglu, S. Kirazli and H. C. Firat, "In vivo Hemostatic Effect of the Medicinal Plant Extract Ankaferd Blood Stopper in Rats Pretreated with Warfarin," Clinical and Applied Thrombosis/Hemostasis, Vol. 15, No. 3, 2009, pp. 270-276. doi: $10.1177 / 1076029608329578$

[36] A. Kosar, H. S. Cipil, A. Kaya, B. Uz, I. C. Haznedaroglu, H. Goker, O. Ozdemir, S. Ercetin, S. Kirazli and H. C. Firat, "The Efficacy of Ankaferd Blood Stopper in Antithrombotic Drug-Induced Primary and Secondary Hemostatic Abnormalities of a Rat-Bleeding Model," Blood Coagul Fibrinolysis, Vol. 20, No. 3, 2009, pp. 185-190. doi:10.1097/MBC.0b013e32831c4cb0

[37] E. Kilic, D. U. Cetinkaya, I. Haznedaroglu, M. Turgut, S. Aksu, S. Kirazlı and H. Goker, "The Effects of Ankaferd Blood Stopper on in vitro Mesenchymal Stem Cell Development," Proceedings of 34th National Congress of Hametology Cesme Izmir, Turkey, 8-11th October 2008, No. B065.

[38] T. Niemi, T. Svartling, M. Syrjala, S. Asko-Seljavaara and P. Rosenberg, "Haemostatic Disturbances in Burned Patients during Early Excision and Skin Grafting," Blood Coagul Fibrinolysis, Vol. 9, No. 1, 1998, pp. 19-28. doi:10.1097/00001721-199801000-00003

[39] H. Goker, I. C. Haznedaroglu, S. Ercetin, S. Kirazli, U. Akman, Y. Ozturk and H. C. Firat, "Hemostatic Actions of Folkloric Medicinal Plant Extract Ankaferd Blood Stopper," Journal of International Medical Researsh, Vol. 36, No. 1, 2008, pp. 163-170.

[40] T. Purnak, E. Ozaslan, Y. Beyazıt and I. C. Haznedaroglu, "Upper Gastrointestinal Bleeding in a Patient with Defective Hemostasis Succesfully Treated with Ankaferd Blood Stopper," Phytotherapy Research, 30 July 2010, Epublication.

[41] A. C. Ucar, U. Calıskan, I. C. Haznedaroglu and H. Goker, "Hemostatic Actions of the Folkloric Medicinal Plant extract Ankaferd Blood Stopper," Journal of International Medical Research, Vol. 36, No. 1, 2008, pp. 163-170.

[42] G. Lippi, L. Ippolito and G. Cervellin, "Disseminated Intravacular Cougulation in Burn Injury," Seminer Thromb Hemost, Vol. 36, No. 4, 2010, pp. 429-436. doi:10.1055/s-0030-1254051

[43] J. P. Barret and P. A. Gomez, "Disseminated Intravascular Coagulopathy: A Rare Entity in Burn Injury," Burns, Vol. 31, No. 3, 2005, pp. 354-357. doi:10.1016/j.burns.2004.11.006 